\section{MEETINGS AND COURSES}

\section{Annual courses}

Title: Courses in Sexual and Reproductive Health. Venue: Warwick, UK. Details: See display advertisement on inside back cover.

\section{Throughout 2003}

Title: Current Issues in Sexual and Reproductive Health. Venue: London, UK. Details: See display advertisement on page 50

\section{Throughout 2003}

Title: Various Courses. Venue: The Sandyford Initiative, Glasgow, UK Details: See display advertisement on page 51

\section{5-7 February 2003}

Title: Basic Theoretical Course in Family Planning. Venue: Primary Care Development an Resource Centre, Southampton, UK. Details: Will fulfil criteria for the new DFFP syllabus and is suitable for doctors updating their knowledge. Accreditation: PGEA and DFFP. Information Wessex Course Centre, Mailpoint 0802, South Academic Block, Southampton General Hospital, Tremona Road, Southampton SO16 6YD, UK Tel: +44 (0) 238079 6844. Fax: +44 (0) 238079 8554.E-mail: janice.rosher@suht.swest.nhs.uk.

\section{March 2003}

Title: $113^{\text {th }}$ Meeting of the Northern Interbranch Doctor's Group. Venue: Tapton Hall, Sheffield, UK. Details: A 1-day update for members an guests on reproductive and sexual health, to include a talk by Professor Drife on media scares and hormones, an update on syphilis and talks on other subjects to be confirmed. Accreditation: PGEA, CME and FF applied for. Information: D Gillian R Wight, Roulston Cottage, Suttonunder-Whitestonecliffe, Thirsk, North Yorkshire YO7 2PS, UK. Tel/Fax: +44 (0) 1845597329.

\section{March 2003}

Title: Spring Meeting of the NW Society of Sexual Medicine and Family Planning. Venue: Maritime Museum, Albert Dock, Liverpool, UK. Details (morning) adolescent sexual problems; sex, drugs and no (birth) control; (afternoon) issues an concerns around the menopause; liquid-based cytology. Accreditation: PGEA, FFP (CME) and FFP. Information: Mavis L Barnard, 7 Regen Road, Chorley PR7 2DH, UK. Tel: +44 (0) 1257267657.

\section{2-14 March 2003}

Title: Theoretical Training Course of the Diploma in Family Planning and Reproductive Health. Venue: The Education Centre, Fieldhead Hospital, Wakefield, UK. Details: See display advertisement on page 49 .

\section{March 2003}

Title: Update in Women's Health. Venue Postgraduate Medical Centre, Freeman Hospital, Newcastle-upon-Tyne, UK. Details: Open to al doctors and health care staff working in or with an interest in family planning and reproductive health care, organised by Newcastle Contraception and Sexual Health Service. Accreditation: PGEA, FFP and RNC. Information: Linda O'Donnell, Diabetes Centre, Newcastle General Hospital, Westgate Road, Newcastle-upon-Tyne NE4 6BE, UK. Tel: +44 (0) 191256 3393. Fax: +44 (0) 1912563212 . Email: linda.odonnell@ncht.northynhs.uk

\section{March 2003}

Title: Contraception and Sexual Health at the Coalface - An Update. Venue: Royal Shrewsbury Hospital, Shrewsbury, UK. Details: Topics to include COC update and medico-legal aspects, the crossover between family planning and GU medicine, perimenopausal contraception, IUS brantub and audit. Booking form and furthe information available on website (www.wmafpd org.uk) from early February 2003. Accreditation: 5 hours PGEA; FFP accreditation applied for Information: Dr Ruth Fear, 71 St Helen's Road Solihull, West Midlands B91 2DB, UK. Tel: 01217055146 (evenings). E-mail: symposium @wmafpd.org.uk

\section{April 2003}

Title: 3-Day DFFP Course. Venue: London, UK. Details: A $2-\frac{1}{2}$ day course suitable for doctor wishing to obtain the Diploma of the FFPRHC (o the RCOG). The course covers basic family planning aspects, and is organised by the Sexua \& Reproductive Health Training Partnership. Also provided is a $1 / 2$-day optional IUD module fo those doctors with a special interest in family planning and who are considering going on to gain their Letter of Competence in Intrauterine Techniques (LoC IUT). Accreditation: FFP and PGEA approved. Information: Palmela Witter, Training Administrator, The Sexual \& Reproductive Health Training Partnership, Southwark PCT, St Giles Hospital, St Giles Road, London SE5 7RN, UK. Tel: +44 (0) 20777 3322. Fax: +44 (0) 207771 3338. E-mail selfptu@ southwarkpct.nhs.uk

\section{1-2 April 2003}

Title: DFFP Basic Training Theory Course. Venue Harris Park Conference Centre, Preston, UK. Details: Suitable for family planning doctors updating. Accreditation: Suitable for CME/RCOG PGEA and FFP accreditation applied for Information: Ann Conti, Regional Training Department, 63-65 Palatine Road, Manchester M20 3LJ, UK. Tel: +44 (0) 161434 8629. Fax: +44 (0) 161448 1889. E-mail: a.conti@man.ac.uk

\section{3-4 April 2003}

Title: Basic Course for the Faculty of Family Planning and Reproductive Health. Venue: Institute of Child Health, London, UK. Details Organised by $\mathrm{Dr}$ Elizabeth Stephens. Accreditation: First part of DFFP and PGEA. Information: Dawn Atkinson, First Floor, Margaret Pyke Centre, 73 Charlotte Street, London W1T 4PL, UK. Tel: +44 (0) 207530 3608. Fax: +44 (0) 2075303646

\section{8-30 April 2003}

Title: Potential Instructing Doctors Course Venue: London, UK. Details: See display advertisement on page 52

\section{May 2003}

Title: Update in Family Planning. Venue: Western General Hospital, Edinburgh, UK. Details: Full day update programme to cover third-generation pills, breast disease and hormones, contraception after abortion, and 'hot topics'. Guest Speaker: Dr Kaye Wellings. Accreditation: PGEA and FFP reaccreditation applied for. Information: Dr Ailsa Gebbie, Family Planning Service, 18 Dean Terrace, Edinburgh EH4 1NL, UK. Tel: +44 (0) 131315 4827. Fax: +44 (0) 1313322931.

\section{6-18 May 2003}

Title: Weekend Family Planning Theory Course for Doctors. Venue: Northwick Park Hospital, Harrow, UK. Details: Modular course incorporating the new DFFP syllabus. Suitable for updating and continuing professional development. Accreditation: FFP and PGEA approval applied for. Information: Diane Price, Family Planning Training Office, Frances Ward Maternity Block, The North West Hospitals NHS Trust, Watford Road, Harrow HA1 3UJ, UK. Tel: +44 (0) 208869 3127. Fax: +44 (0) 208869 2903. E-mail: bela.reed@ nwlh.nhs.uk

\section{2-23 May 2003}

Title: Faculty of Family Planning and Reproductive Health Care AGM and Annual Symposium. Venue: Manchester Conference Centre, Manchester, UK. Details: See display advertisement on page 52 .

\section{July 2003}

Title: 4-Day STIF and DFFP Course. Venue: London, UK. Details: A one-off 4-day course comprising 2-day contraceptive modules and 2day sexually transmitted infection modules in the form of an STI Foundation (STIF) course. A 2 day modular contraceptive theory course suitable for doctors wishing to obtain the contraceptive modules of the new training scheme for the Diploma of the FFPRHC (of the RCOG), plus a 2 day sexually transmitted infection modular course suitable for the STI modules of the new DFFP Accreditation: FFP and PGEA approved Information: Palmela Witter, Training Administrator, The Sexual \& Reproductive Health Training Partnership, Southwark PCT, St Giles Hospital, St Giles Road, London SE5 7RN, UK. Tel: +44 (0) 207771 3322. Fax: +44 (0) 20777 3338. E-mail: selfptu@ southwarkpct.nhs.uk

\section{4-25 July 2003}

Title: Basic Course for the Faculty of Family Planning and Reproductive Health. Venue: Institute of Child Health, London, UK. Details Organised by $\mathrm{Dr}$ Elizabeth Stephens. Accreditation: First part of DFFP and PGEA. Information: Dawn Atkinson, First Floor, Margaret Pyke Centre, 73 Charlotte Street, London W1T 4PL, UK. Tel: +44 (0) 207530 3608. Fax: +44 (0) 2075303646

\section{October 2003}

Title: 4-Day STIF and DFFP Course. Venue London, UK. Details: Two 2-day courses held over consecutive weeks comprising 2-day contraceptive modules and 2-day sexually transmitted infection modules in the form of an STI Foundation (STIF) course. A 2-day modula contraceptive theory course suitable for doctors wishing to obtain the contraceptive modules of the new training scheme for the Diploma of the FFPRHC (of the RCOG), plus a 2-day sexually transmitted infection modular course suitable for the STI modules of the new DFFP. Accreditation FFP and PGEA approved. Information: Palmela Witter, Training Administrator, The Sexual \& Reproductive Health Training Partnership Southwark PCT, St Giles Hospital, St Giles Road, London SE5 7RN, UK. Tel: +44 (0) 20777 3322. Fax: +44 (0) 207771 3338. E-mail: selfptu@ southwarkpct.nhs.uk

\section{7-11 February 2004}

Title: East Meets West. Venue: Chiang Mai, Thailand. Details: See display advertisement on page 50

There is a charge of $£ 50$ + VAT for each meeting/course publicised in this section of the Journal. This will guarantee inclusion in the issue requested. For guaranteed inclusion in the April issue all course details should be with Sarah Monger by 24 February 2003. For a booking form please contact Sarah Monger at PMH Publications, PO Box 100, Chichester, West Sussex, PO18 8HD, UK. Tel: +44 (0) 1243 576444. Fax: +44 PO18 8HD, UK. Tel: +44 (0) 1243576444 .Fax: +44
(0) 1243 576456. E-mail: adsales@ $@$ pmh.uk.com 


\section{But is she positive?}

Your next patient is pregnant but doesn't want to be.

Where next? As a registered charity since 1968, BPAS has offered affordable abortion care for women who are unable or don't want to use NHS services. We provide almost 50,000 abortions a year (including service agreements) and can offer all the professional help your patient needs.

BPAS has a nationwide network of clinics and consultation centres. There are no long waits for appointments. We can offer a choice of times, clinics and procedures. All it takes to arrange an appointment is one call to the BPAS Actionline on 08457304030 . Your patient can call us herself - or you can call on her behalf.

\section{ACTIONLINE 08457304030}

BPAS positively the best service

For further information on all BPAS services including emergency contraception, sterilisation and vasectomy, contact Susan Bradley, Marketing Officer on 01564796108 or visit the BPAS website at www.bpas.org

Theoretical Training Course The Diploma in Family Planning \& Reproductive Health

\section{Wednesday 12th, Thursday 13th \& Friday 14th March 2003}

to be held at:

The Education Centre

Fieldhead Hospital

Wakefield

Course format: Lectures,

Workshops and Case Studies.

Maximum of 40 delegates

PGEA \& Faculty of Family Planning Accreditation applied for

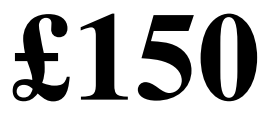

(inc FFP log book, lunches and refreshments)

Apply to Mrs Michelle Gilbert Medical Education Services Pinderfields General Hospital Aberford Road Wakefield

WF1 4DG

Tel: 01924212263
Do you have a position

$$
\text { to fill? }
$$

A re you organising

a course in reproductive

health care?

A re you interested

in planning how best

to prom ote your

product or service?

For d e tails p lease contact:

$\mathrm{S}$ a r a h M o n g e r

a $t$ P M H P b lic a tion

T e 1: + 44 (0) 1243576444

$\mathrm{F} a \mathrm{x}:+44(0) 1243576456$

Em a il: a d s a les@pm h.uk.com 